\title{
ANALISIS PENDAPATAN DAN KELAYAKAN USAHATANI PADI DI KECAMATAN PITU RIAWA KABUPATEN SIDRAP
}

\author{
Income and Feasibility Studies of Paddy Farming \\ in Pitu Riawa Subdistrict Sidrap District \\ Muhammad Imam Ma'ruf*, Citra Ayni Kamaruddin, Arief Muharief \\ Program Studi Ekonomi Pembangunan, Fakultas Ekonomi, Universitas Negeri Makassar, Makassar \\ *Kontak penulis: muhammadimammaruf@unm.ac.id
}

\begin{abstract}
Food needs will continue to increase due to year by year, Indonesia's population continues to increase, while the amount of food production cannot compensate for the increase in population. To guarantee national food security, the Indonesian government continues to strive to procure sufficient amounts of rice, including the use of highyielding seeds, balanced and efficient use of fertilizers, control of pests and diseases, etc. These efforts are only focused on achieving targeted rice production but have not paid attention to the level of income obtained by farmers when cultivating rice compared to cultivating other agricultural commodities. The research was aimed to: (1) determine the income level of a rice farmer, especially in Sidrap District, which is a rice barn area in South Sulawesi Province; and (2) to determine the feasibility of rice farming in the area. One indicator of the feasibility of rice farming can be known based on the value of R / C ratio as well as Break Even Point (BEP) production and Break Even Point (BEP) prices. This study found that the level of income obtained by rice farmers in Pitu Riawa Subdistrict, Sidrap District was Rp. 13,624,672 / ha and was feasible to be cultivated with $\mathrm{R} / \mathrm{C}$ ratio > 4.24; $\mathrm{BEP}$ production of $358 \mathrm{~kg}$; BEP price of IDR 1,152 / kg.
\end{abstract}

Keywords: break-even point; feasibility; paddy.

\begin{abstract}
Abstrak
Kebutuhan pangan akan terus meningkat disebabkan dari tahun ke tahun, jumlah penduduk Indonesia terus mengalami peningkatan, sedangkan jumlah produksi pangan tidak dapat mengimbangi peningkatan jumlah penduduk. Dalam rangka menjamin ketahanan pangan nasional, pemerintah Indonesia terus berupaya untuk melakukan pengadaan padi dalam jumlah yang cukup, di antaranya penggunaan bibit unggul dengan produktivitas tinggi, penggunaan pupuk berimbang dan efisien, serta pengendalian hama dan penyakit. Upaya-upaya tersebut hanya fokus dalam mencapai produksi padi yang ditargetkan, namun belum memperhatikan tingkat pendapatan yang diperoleh oleh petani bila membudidayakan tanaman padi dibandingkan membudidayakan komoditas pertanian lainnya. Penelitian ini bertujuan untuk: (1) mengetahui tingkat pendapatan petani padi, khususnya di Kabupaten Sidrap yang merupakan daerah lumbung padi di Provinsi Sulawesi Selatan dan (2) mengetahui kelayakan usahatani padi di daerah tersebut. Salah satu indikator kelayakan usahatani padi dapat diketahui berdasarkan nilai R/C ratio serta Break Even Point (BEP) produksi dan Break Even Point (BEP) harga. Hasil penelitian ini menunjukkan bahwa tingkat pendapatan yang diperoleh oleh petani padi di Kecamatan Pitu Riawa Kabupaten Sidrap sebesar Rp 13.626.672/MT/ha dan layak untuk diusahakan dengan R/C ratio > 4,24; BEP produksi sebesar 358 kg; BEP harga sebesar Rp 1.152/kg.
\end{abstract}

Keywords: titik impas; kelayakan; padi. 
Sitasi: Ma'ruf, M. I., C. A. Kamaruddin, A. Muharief, 2019. Analisis Pendapatan dan Kelayakan Usahatani Padi di Kecamatan Pitu Riawa Kabupaten Sidrap, JSEP 15 (3): $193-204$.

\section{Pendahuluan}

Indonesia merupakan negara yang sedang melaksanakan pembangunan di segala bidang. Salah satu sektor yang menjadi sektor yang diandalkan adalah sektor pertanian. Hal ini disebabkan sektor pertanian hingga saat ini masih memegang peranan penting dalam mengurangi kemiskinan karena baik secara langsung maupun tidak langsung, pembangunan pertanian berkaitan dengan upaya peningkatan kesejahteraan petani.

Pengembangan tanaman pangan merupakan bagian dari sektor pertanian dengan tujuan untuk mewujudkan kondisi terpenuhinya kebutuhan pangan dengan gizi yang cukup bagi penduduk untuk menjalani hidup sehat dan produktif. Padi merupakan komoditas dari tanaman pangan. Komoditas padi merupakan salah satu komoditas yang menjadi perhatian khusus dari pemerintah karena merupakan salah satu bahan makanan pokok masyarakat Indonesia. Kebutuhan pangan akan terus meningkat disebabkan dari tahun ke tahun, jumlah penduduk Indonesia terus mengalami peningkatan, sedangkan jumlah produksi pangan tidak dapat mengimbangi peningkatan jumlah penduduk.

Dalam rangka menjamin ketahanan pangan nasional, pemerintah Indonesia terus berupaya untuk melakukan pengadaan padi dalam jumlah yang cukup. Berbagai upaya telah dilakukan pemerintah dalam meningkatkan produksi padi untuk mencapai target Program Peningkatan Produksi Beras Nasional (P2BN), di antaranya penggunaan bibit unggul dengan produktivitas tinggi, penggunaan pupuk berimbang dan efisien, serta pengendalian hama dan penyakit. Upaya-upaya tersebut hanya fokus dalam mencapai produksi padi yang ditargetkan, namun belum memperhatikan tingkat pendapatan yang diperoleh oleh petani bila membudidayakan tanaman padi dibandingkan membudidayakan komoditas pertanian lainnya.

Secara umum, pendapatan yang diterima petani belum memadai dibanding dengan jerih payah yang telah dikeluarkannya ditambah dengan risiko kegagalan panen. Tingkat pendapatan yang diterima petani bergantung pada berbagai faktor yang mempengaruhi produktivitas lahan. Beberapa indikator menunjuukkan bahwa di beberapa daerah banyak petani yang belum menikmati hasil jerih payahnya secara memadai (Mardiyanto, et al., 2005). Sebagai seorang manager pertanian, seorang petani tentunya harus bisa mengambil keputusan dalam penentuan komoditas yang akan dibudidayakan yang lebih menguntungkan dan dapat memenuhi kebutuhan hidup. Padi tidak hanya diusahakan karena peranannya sebagai salah satu makanan pokok yang makin hari terasa penting karena mengandung gizi dan energi yang cukup bagi tubuh manusia. Oleh karena itu, penelitian ini dilakukan dengan tujuan untuk mengetahui tingkat pendapatan petani padi, khususnya di Kabupaten Sidrap yang merupakan daerah lumbung padi di Provinsi Sulawesi Selatan dan untuk mengetahui kelayakan usahatani padi di daerah tersebut. 


\section{Metode Penelitian}

Penelitian ini merupakan penelitian deksriptif, yakni penelitian yang menyajikan gambaran lengkap mengenai fenomena sosial di Kecamatan Pitu Riawa Kabupaten Sidrap untuk mengukur tingkat pendapatan petani padi dan kelayakan usahatani padi.

Jenis data yang digunakan dalam penelitian ini menurut dimensi waktu, yaitu silang tempat (cross-section). Populasi dalam penelitian ini adalah seluruh petani padi yang bertempat di Kecamatan Pitu Riawa Kabupaten Sidrap. Pemilihan lokasi ini didasarkan secara purposive sampling dilihat dari luas tanam padi yang dihasilkan. Pengambilan sampel dilakukan dengan Simple Random Sampling, terdapat 95 petani padi yang dijadikan sebagai sampel. Teknik pengumpulan data yang dilakukan adalah wawancara.

Menurut Suratiyah (2016), pendapatan petani meliputi upah tenaga kerja keluarga sendiri, upah petani sebagai manajer, bunga modal sendiri, dan keuntungan. Pendapatan dapat dirumuskan sebagai berikut:

$$
\begin{aligned}
& I=R-C \\
& R=Y \cdot P y \\
& I=(Y \cdot P y)-C
\end{aligned}
$$

$$
\begin{array}{ll}
\text { Keterangan: } & \mathrm{I}=\text { Pendapatan } \\
\mathrm{R} & =\text { Penerimaan } \\
\mathrm{Py} & =\text { Harga produksi } \\
\mathrm{Y} & =\text { Produksi Total } \\
\mathrm{C} & =\text { Biaya eksplisit total }
\end{array}
$$

Menurut Suratiyah et al. (2003), suatu usahatani dikatakan layak untuk dikembangkan jika memenuhi kriteria sebagai berikut:

a. Kriteria usahatani dikatakan layak jika $\mathrm{R} / \mathrm{C}>1$. $\mathrm{R} / \mathrm{C}$ ratio merupakan perbandingan antara penerimaan (revenue) dengan biaya (cost). $\mathrm{R} / \mathrm{C}$ ratio dapat dirumuskan sebagai berikut:

$$
\begin{gathered}
\alpha=\frac{\mathrm{R}}{\mathrm{C}} \\
\mathrm{R}=\mathrm{Y} \cdot \mathrm{Py} \\
\mathrm{C}=\mathrm{FC}+\mathrm{VC} \\
\alpha=\frac{\mathrm{Y} \cdot \mathrm{P}_{\mathrm{y}}}{\mathrm{FC}+\mathrm{VC}}
\end{gathered}
$$

$$
\text { Keterangan: } \quad \begin{aligned}
& \alpha=\text { Revenue cost ratio } \\
& \mathrm{R}=\text { Penerimaan } \\
& \mathrm{C}=\text { Total biaya } \\
& \mathrm{Py}=\text { Harga produksi } \\
& \mathrm{Y}=\text { Produksi total } \\
& \mathrm{FC}=\text { Biaya tetap } \\
& \mathrm{VC}=\text { Biaya variabel }
\end{aligned}
$$


b. Kriteria usahatani dikatakan layak jika produksi > BEP produksi. BEP produksi $(\mathrm{kg})$ menghasilkan perhitungan sebagai berikut:

$$
\text { BEP produksi }(\mathrm{kg})=\frac{\mathrm{FC}}{\mathrm{P}_{\mathrm{y}}-\mathrm{AVC}}
$$

Keterangan: $\quad \mathrm{FC}=$ Biaya tetap

$\mathrm{AVC}=$ Biaya variabel per unit

Py = Harga produksi

c. Kriteria usahatani dikatakan layak jika harga > BEP harga. BEP harga $(\mathrm{Rp} / \mathrm{kg})$ menghasilkan perhitungan sebagai berikut:

$$
\mathrm{BEP} \text { harga }(\mathrm{Rp} / \mathrm{kg})=\frac{\mathrm{C}}{\mathrm{Y}}
$$

$\begin{array}{ll}\text { Keterangan : } & \mathrm{C}=\text { Biaya total } \\ \mathrm{Y} & =\text { Produksi total }\end{array}$

Analisis Break Even Point adalah suatu teknik analisa untuk mempelajari hubungan antara biaya tetap, biaya variabel, keuntungan dan volume kegiatan. Kegunaan analisis ini adalah sebagai landasan atau dasar untuk merencanakan kegiatan operasional dalam mencapai laba tertentu (profit planning), sebagai dasar atau landasan untuk mengendalikan kegiatan operasi yang sedang berjalan, sebagai bahan pertimbangan dalam menentukan harga jual, dan sebagai pertimbangan dalam pengambilan keputusan produksi/penjualan (Lumintang, 2013). Hipotesis penelitian ini dapat dirumuskan sebagai berikut:

Hipotesis 1 : Diduga usahatani padi di Kecamatan Pitu Riawa Kabupaten Sidrap layak diusahakan dengan nilai R/C $>1$.

Hipotesis 2 : Diduga usahatani padi di Kecamatan Pitu Riawa Kabupaten Sidrap layak diusahakan dengan produksi total padi > BEP produksi.

Hipotesis 3 : Diduga usahaani padi di Kecamatan Pitu Riawa Kabupaten Sidrap layak diusahakan dengan harga produk padi > BEP harga.

Uji hipotesis dilakukan dengan metode one sample t test (uji t). Dengan metode ini, nilai $\mathrm{R} / \mathrm{C}, \mathrm{BEP}$ produksi dan $\mathrm{BEP}$ harga dibandingkan dengan test value tertentu (Ma'ruf dan Suratiyah, 2010).

a. $\mathrm{R} / \mathrm{C}$ ratio. Uji t ini menggunakan nilai 1 sebagai test value, sedangkan hipotesis yang diuji adalah sebagai berikut :

$$
\begin{aligned}
& \mathrm{H}_{0}: \mathrm{R} / \mathrm{C} \leq 1 \\
& \mathrm{H}_{1} \quad: \mathrm{R} / \mathrm{C}>1 \\
& \mathrm{H}_{0} \text { ditolak jika } \mathrm{t}_{\text {hitung }}>\mathrm{t} \text { tabel dan } \mathrm{H}_{0} \text { diterima jika } \mathrm{t}_{\text {hitung }}<\mathrm{t}_{\text {tabel. }} \text {. }
\end{aligned}
$$

b. BEP produksi. Uji $t$ ini menggunakan nilai BEP produksi sebagai test value, sedangkan hipotesis yang diuji adalah sebagai berikut:

$\mathrm{H}_{0} \quad$ : Total produksi $\leq \mathrm{BEP}$ produksi

$\mathrm{H}_{1}$ : Total produksi $>$ BEP produksi

$\mathrm{H}_{0}$ ditolak jika $\mathrm{t}_{\text {hitung }}>\mathrm{t}_{\text {tabel }}$ dan $\mathrm{H}_{0}$ diterima jika $\mathrm{t}_{\text {hitung }}<\mathrm{t}_{\text {tabel. }}$. 
c. BEP harga. Uji $\mathrm{t}$ ini menggunakan nilai BEP harga sebagai test value, sedangkan hipotesis yang diuji adalah sebagai berikut :

$$
\begin{aligned}
& \mathrm{H}_{0} \text { : Harga produk } \leq \mathrm{BEP} \text { harga } \\
& \mathrm{H}_{1} \text { : Harga produk }>\mathrm{BEP} \text { harga } \\
& \mathrm{H}_{0} \text { ditolak jika } \mathrm{t} \text { hitung }>\mathrm{t} \text { tabel dan } \mathrm{H}_{0} \text { diterima jika } \mathrm{t}_{\text {hitung }}<\mathrm{t} \text { tabel. }
\end{aligned}
$$

\section{Hasil dan Pembahasan}

Dalam penelitian ini, petani padi membudidayakan lebih dari satu varietas padi di antaranya varietas Mekongga, Ciherang, Cigeulis, Inpari, dan Situ Bagendit. Kelebihan dari masing-masing varietas bukan hanya dari segi harganya, akan tetapi dapat dilihat pula dari ketahanan varietas padi terhadap serangan hama dan penyakit, serta tingkat produktivitas masing-masing varietas padi yang berbeda satu dengan yang lainnya. Peningkatan pendapatan dan produksi petani padi sawah tidak terlepas dari proses pemeliharaan yang diberikan oleh tiap-tiap petani baik secara tradisional maupun modern (Supartama et al., 2013). Perbandingan produksi rata-rata masing-masing varietas padi yang telah digunakan oleh petani padi di Kecamatan Pitu Riawa Kabupaten Sidrap dapat dilihat pada Tabel 1.

\section{Tabel 1}

Perbandingan Produksi Rata-rata Varietas Padi yang Dibudidayakan Petani di Kecamatan Pitu Riawa Kabupaten Sidrap

\begin{tabular}{llccrr}
\hline No. & Varietas Padi & $\begin{array}{c}\text { Luas Lahan } \\
\text { (ha) }\end{array}$ & $\begin{array}{c}\text { Produktivitas } \\
\text { (ton/ha) }\end{array}$ & $\begin{array}{r}\text { Produksi } \\
\text { (kg) }\end{array}$ & $\begin{array}{c}\text { Persentase } \\
\text { (\%) }\end{array}$ \\
\hline 1. & Mekongga & 0,49 & 3,61 & 1.768 & 34,64 \\
2. & Ciherang & 0,32 & 3,97 & 1.271 & 24,90 \\
3. & Cigeulis & 0,25 & 3,63 & 907 & 17,77 \\
4. & Situ Bagendit & 0,03 & 2,70 & 81 & 1,59 \\
5. & Inpari & 0,30 & 3,51 & 1.053 & 20,63 \\
6. & Varietas & 0,01 & 2,40 & 24 & 0,47 \\
& Lainnya & & & & \\
\hline
\end{tabular}

Berdasarkan Tabel 1. dapat dilihat bahwa varietas Ciherang merupakan varietas padi dengan produktivitas tertinggi dari berbagai varietas padi yang dibudidayakan oleh petani padi di Kecamatan Pitu Riawa Kabupaten Sidrap. Varietas unggul baru yang sebagian dihasilkan melalui penelitian telah dikembangkan oleh petani. Varietas unggul baru ini merupakan inovasi teknologi yang dihasilkan oleh Badan Litbang Pertanian untuk meningkatkan produksi padi (Sudarto, et al., 2018). Dari hasil produksi padi, para petani padi menjual dalam bentuk Gabah Kering Panen (GKP). Untuk mengetahui rata-rata penerimaan yang diperoleh para petani padi di Kecamatan Pitu Riawa Kabupaten Sidrap dapat dilihat pada Tabel 2. 
Tabel 2

Penerimaan Rata-rata Petani Padi di Kecamatan Pitu Riawa Kabupaten Sidrap

\begin{tabular}{clccr}
\hline No. & Varietas Padi & Produksi $\mathbf{( k g )}$ & Harga (Rp/kg) & Penerimaan (Rp) \\
\hline 1. & Mekongga & 1.768 & 4.912 & 8.687 .105 \\
2. & Ciherang & 1.271 & 4.943 & 6.280 .468 \\
3. & Cigeulis & 907 & 4.952 & 4.490 .737 \\
4. & Situ Bagendit & 81 & 5.279 & 427.632 \\
5. & Inpari & 1.053 & 4.709 & 4.959 .473 \\
6. & Lainnya & 24 & 4.736 & 113.684 \\
\hline \multicolumn{2}{c}{ Jumlah } & $\mathbf{5 . 1 0 4}$ & $\mathbf{4 . 8 9 0}$ & $\mathbf{2 4 . 9 5 9 . 0 9 9}$ \\
\hline
\end{tabular}

Berdasarkan Tabel 2. dapat dilihat bahwa para petani padi bisa memperoleh rata-rata penerimaan sebesar Rp 24.959.099/MT dari rata-rata produksi sebesar 5.104 $\mathrm{kg}$ dan luas lahan 1,4 hektar. Hal ini menunjukkan bahwa perbedaan jumlah produksi dan harga jual setiap varietas padi mempunyai pengaruh terhadap jumlah penerimaan yang didapatkan oleh para petani padi di Kecamatan Pitu Riawa Kabupaten Sidrap.

Biaya merupakan semua pengorbanan yang perlu dilakukan untuk proses produksi, yang dinyatakan dengan satuan uang menurut harga pasar yang berlaku, baik yang sudah terjadi maupun yang akan terjadi. Biaya produksi dalam usahatani padi merupakan semua pengeluaran yang diperlukan petani padi untuk menghasilkan produksi dalam satu kali musim tanam.

Biaya produksi padi dapat digolongkan atas dasar hubungan perubahan volume produksi, yaitu biaya tetap dan biaya variabel. Dalam penelitian ini, yang termasuk dalam biaya tetap adalah biaya penyusutan peralatan dan biaya lain-lain, sedangkan untuk biaya variabel adalah biaya bibit, biaya pupuk, biaya pestisida, dan biaya tenaga kerja. Penjumlahan kedua biaya tersebut dapat menghasilkan biaya total dalam satu kali musim tanam untuk petani padi di Kecamatan Pitu Riawa Kabupaten Sidrap. Untuk lebih jelas rincian biaya tersebut dapat dilihat pada Tabel 3.

Tabel 3

Struktur Biaya Usahatani Padi di Kecamatan Pitu Riawa Kabupaten Sidrap per Musim Tanam

\begin{tabular}{|c|c|c|c|c|}
\hline No. & & ruktur Biaya & Jumlah (Rp) & Persentase (\%) \\
\hline \multirow{5}{*}{1.} & \multirow{4}{*}{ Biaya Variabel } & Biaya Bibit & 1.011 .605 & 17,19 \\
\hline & & Biaya Pupuk & 1.177.079 & 20,00 \\
\hline & & Biaya Pestisida & 482.942 & 8,21 \\
\hline & & Biaya Tenaga Kerja & 1.774 .847 & 30,16 \\
\hline & \multicolumn{2}{|c|}{ Biaya Variabel Total } & 4.446 .473 & 75,56 \\
\hline \multirow{5}{*}{2.} & \multirow{3}{*}{ Biaya Tetap } & Biaya Penyusutan & 249.769 & 4,25 \\
\hline & & Peralatan & & \\
\hline & & Biaya Lain-lain & 1.188 .316 & 20,19 \\
\hline & \multicolumn{2}{|c|}{ Biaya Tetap Total } & 1.438 .085 & 24,44 \\
\hline & \multicolumn{2}{|c|}{ Biaya Total } & 5.884 .558 & 100,00 \\
\hline
\end{tabular}


Berdasarkan Tabel 3. dapat dilihat bahwa dalam satu kali musim tanam petani mengeluarkan biaya total sebesar Rp 5.884.558. Biaya total yang dikeluarkan petani padi merupakan jumlah dari biaya tetap total ditambah dengan biaya variabel total selama satu kali musim tanam. Biaya tenaga kerja merupakan biaya dengan nilai persentase tertinggi karena kegiatan berusahatani padi di Kecamatan Pitu Riawa Kabupaten Sidrap merupakan kegiatan yang padat karya.

Pendapatan para petani padi merupakan hasil pengurangan dari penerimaan yang diterima oleh para petani padi dengan besarnya biaya total yang dikeluarkan. Secara umum, peningkatan produksi suatu usahatani merupakan indikator keberhasilan dari usahatani yang bersangkutan, namun tingginya produksi suatu komoditas yang diperoleh dalam per satuan luas lahan belum menjamin tingginya pendapatan usahatani padi sawah yang dipengaruhi oleh harga yang diterima petani dan biaya-biaya penggunaan input usahatani (Munizar dan Tangakesalu, 2019). Dalam penelitian ini pendapatan yang diterima oleh petani padi di Kecamatan Pitu Riawa Kabupaten Sidrap dapat dilihat pada Tabel 4.

Berdasarkan Tabel 4 dapat dilihat bahwa rata-rata pendapatan petani padi di Kecamatan Pitu Riawa Kabupaten Sidrap sebesar Rp 13.624.672/MT/ha atau dengan kata lain, petani padi memperoleh pendapatan sebesar Rp 4.541.447/bulan. Nilai ini berada di atas Upah Minimum Provinsi (UMP) sebesar Rp 2.647.000.

\section{Tabel 4}

Pendapatan Rata-rata Petani Padi di Kecamatan Pitu Riawa Kabupaten Sidrap per Musim Tanam

\begin{tabular}{clrr}
\hline No. & Uraian & $\begin{array}{c}\text { Jumlah }(\mathbf{R p}) \\
\text { per } \mathbf{1 , 4} \text { ha }\end{array}$ & $\begin{array}{c}\text { Jumlah }(\mathbf{R p}) \\
\text { per ha }\end{array}$ \\
\hline 1. & Penerimaan & 24.959 .099 & 17.827 .928 \\
2. & Biaya Total & 5.884 .558 & 4.203 .256 \\
3. & Pendapatan & 19.074 .541 & 13.624 .672 \\
\hline
\end{tabular}

Revenue-Cost ratio (R/C) merupakan salah satu indikator yang dapat digunakan untuk mengetahui kelayakan suatu usaha. Analisis R/C ratio dihitung dengan membandingkan antara penerimaan (revenue) dengan biaya total (cost). Nilai R/C pada usahatani padi di Kecamatan Pitu Riawa Kabupaten Sidrap dapat dilihat pada Tabel 5.

Tabel 5

Nilai R/C Ratio pada Usahatani Padi di Kecamatan Pitu Riawa Kabupaten Sidrap

\begin{tabular}{clc}
\hline No. & \multicolumn{1}{c}{ Uraian } & Nilai \\
\hline 1. & Penerimaan $(\mathrm{R})$ & 24.959 .099 \\
2. & Biaya $(\mathrm{C})$ & 5.884 .558 \\
3. & R/C ratio & 4,24 \\
\hline
\end{tabular}


Berdasarkan Tabel 5 diketahui bahwa R/C $>1$. Hal ini menunjukkan bahwa setiap pengeluaran biaya $\operatorname{Rp} 1,00$ maka akan diperoleh penerimaan sebesar $\operatorname{Rp} 4,24$. Dengan demikian, usahatani padi yang dilakukan oleh petani di Kecamatan Pitu Riawa Kabupaten Sidrap layak untuk diusahakan. Distribusi petani menurut kelayakan usahatani dengan indikator R/C dapat dilihat pada Tabel 6.

Tabel 6

Distribusi Petani Padi Menurut R/C Ratio Usahatani Padi di Kecamatan Pitu Riawa Kabupaten Sidrap

\begin{tabular}{cccc}
\hline No. & R/C ratio & Jumlah Petani (orang) & Persentase (\%) \\
\hline 1. & $\leq 1$ & 0 & 0 \\
2. & $>1$ & 95 & 100 \\
\hline & Jumlah & $\mathbf{9 5}$ & $\mathbf{1 0 0}$ \\
\hline
\end{tabular}

Berdasarkan Tabel 6 diketahui bahwa semua petani memang memiliki nilai $\mathrm{R} / \mathrm{C}$ ratio lebih dari 1 . Selain $\mathrm{R} / \mathrm{C}$ ratio, indikator lainnya yang dapat digunakan untuk mengetahui kelayakan usaha adalah Titik Impas. Titik impas atau break even point merupakan patokan bagi petani dalam berusahatani agar memperoleh keuntungan. Petani harus mengatur sedemikian rupa agar usahatani yang dikelola bergerak di atas titik impas supaya bisa mendapatkan keuntungan.

Bila usahatani yang dikelola petani berada di bawah titik impas maka akan menderita kerugian. Rerata titik impas dalam berusahatani padi di Kecamatan Pitu Riawa Kabupaten Sidrap dapat dilihat pada Tabel 7.

Tabel 7

Titik Impas atau Break Even Point Usahatani Padi di Kecamatan Pitu Riawa Kabupaten Sidrap per Musim Tanam

\begin{tabular}{|c|c|c|c|c|c|}
\hline No. & Uraian & & & Nilai & \\
\hline 1. & Produksi total $(\mathrm{Y})$ & & & 5.104 & $\mathrm{~kg}$ \\
\hline 2. & Biaya total $(\mathrm{C})$ & $\operatorname{Rp}$ & 5.884 .558 & & \\
\hline 3. & Biaya tetap (FC) & $\mathrm{Rp}$ & 1.438 .085 & & \\
\hline 4. & Biaya variabel (VC) & $\mathrm{Rp}$ & & 4.446 .473 & \\
\hline 5. & Biaya variabel per unit (AVC) & $\mathrm{Rp}$ & & 871 & $/ \mathrm{kg}$ \\
\hline 6. & Harga produk (Py) & $\mathrm{Rp}$ & & 4.890 & $/ \mathrm{kg}$ \\
\hline 7. & BEP produksi & & & 358 & $\mathrm{Kg}$ \\
\hline 8. & BEP harga & $\mathrm{Rp}$ & & 1.152 & $/ \mathrm{kg}$ \\
\hline
\end{tabular}

Berdasarkan Tabel 7 dapat diketahui bahwa petani padi tidak akan memperoleh keuntungan ataupun menderita kerugian bila menghasilkan padi selama satu musim tanam sebanyak $358 \mathrm{~kg}$, dan menjual hasil panennya dengan harga Rp 1.152/kg. Bila dalam satu musim tanam petani dapat menghasilkan gabah kering panen (GKP) sebanyak $358 \mathrm{~kg}$ maka petani tidak memperoleh keuntungan ataupun menderita kerugian. Oleh karena itu, agar petani padi dapat memperoleh keuntungan dan tidak menderita kerugian maka hasil panen gabah (GKP) harus ditingkatkan melebihi $358 \mathrm{~kg}$. Cara yang bisa dilakukan petani untuk meningkatkan hasil panen adalah dengan intensifikasi ataupun dengan perluasan lahan. 
Bila dalam setahun petani hanya dapat menjual GKP dengan harga Rp 1.152/kg maka petani tidak memperoleh keuntungan ataupun menderita kerugian. Oleh karena itu, agar petani padi dapat memperoleh keuntungan dan tidak menderita kerugian maka gabah (GKP) harus dijual dengan harga $\mathrm{Rp} 1.152 / \mathrm{kg}$. Dengan demikian, jika terjadi penurunan harga tidak melewati 76,44 \% maka petani tidak rugi. Analisis perubahan harga ditekankan pada harga produk karena pada umumnya harga faktor produksi lebih stabil dibandingkan dengan harga produknya. Dengan kata lain, biaya produksi relatif stabil, sedangkan besarnya penerimaan berfluktuasi mengikuti harga produk.

Pada saat penelitian, harga produk sebesar Rp 4.890/kg dan harga pada saat BEP sebesar Rp 1.152/kg. Harga pada saat BEP adalah sebesar 23,56\% dari harga riil saat penelitian. Ini berarti jika terjadi penurunan harga melebihi 76,44\% maka petani akan menderita kerugian. Hal ini dapat digambarkan seperti yang tampak pada Tabel 8.

Tabel 8

Analisis Perubahan Harga Produk

\begin{tabular}{cccc}
\hline No. & Uraian & $\begin{array}{r}\text { Harga turun } \mathbf{5 0 \%} \\
\text { menjadi Rp 2.445/kg }\end{array}$ & $\begin{array}{c}\text { Harga turun } \mathbf{8 0} \% \\
\text { menjadi Rp 978/kg }\end{array}$ \\
\hline 1. & Penerimaan & $\operatorname{Rp~} 12.479 .280$ & $\operatorname{Rp~} 4.991 .712$ \\
2. & Biaya Total & $\operatorname{Rp} 5.884 .558$ & $\operatorname{Rp~} 5.884 .558$ \\
3. & Pendapatan & $\operatorname{Rp} 6.594 .722$ & $(\operatorname{Rp~} 892.846)$ \\
\hline
\end{tabular}

Berdasarkan perhitungan pada Tabel 8 dijelaskan jika terjadi penurunan harga produk tidak melebihi $76,44 \%$ maka petani tidak akan mengalami kerugian. Angka $76,44 \%$ ini merupakan titik batas yang harus diperhatikan untuk melindungi petani sebagai produsen padi sawah. Berbagai institusi yang berwenang dan mempunyai perhatian khusus bagi petani dapat segera bertindak jika ada kecenderungan penurunan harga mendekati 76,44\% tersebut.

BEP produksi digunakan untuk mengetahui pada jumlah berapakah penjualan yang diperoleh sama dengan besarnya biaya yang dikeluarkan sehingga petani tidak untung dan tidak rugi. Distribusi petani padi berdasarkan BEP produksi dalam berusahatani padi di Kecamatan Pitu Riawa Kabupaten Sidrap dapat dilihat pada Tabel 9.

Tabel 9

Distribusi Petani Padi Menurut BEP Produksi Usahatani Padi di Kecamatan Pitu Riawa Kabupaten Sidrap

\begin{tabular}{cccc}
\hline No. & Uraian & Jumlah Petani (orang) & Persentase (\%) \\
\hline 1. & Produksi $\leq$ BEP Produksi & 0 & 0 \\
2. & Produksi $>$ BEP Produksi & 95 & 100 \\
\hline & Jumlah & $\mathbf{9 5}$ & $\mathbf{1 0 0}$ \\
\hline
\end{tabular}

Berdasarkan Tabel 9 diketahui bahwa 100\% petani padi di Kecamatan Pitu Riawa Kabupaten Sidrap menjual produk gabah kering panen (GKP) dengan jumlah 
di atas BEP produksi. Dengan demikian, petani akan memperoleh keuntungan dalam berusahatani padi. Berdasarkan data pada Tabel 9 dapat pula dihitung luas sawah minimum agar petani padi tidak memperoleh keuntungan maupun menderita kerugian. Caranya dengan membandingkan antara produksi riil pada saat penelitian dengan produksi pada saat BEP dikalikan dengan $1.000 \mathrm{~m}^{2}$. Hasil yang diperoleh adalah $732 \mathrm{~m}^{2}$. Untuk memperoleh keuntungan, petani harus memiliki dan menggarap lahan lebih luas dari $732 \mathrm{~m}^{2}$. Oleh karena itu, petani harus bisa mempertahankan luasan lahan yang dimiliki saat ini dengan tidak menjualnya ataupun mewariskan lahan sawah menjadi beberapa petak kepada pewarisnya. Bila hal ini terjadi maka akan mengurangi luasan lahan yang digarap oleh petani. Berkurangnya luasan lahan akan memengaruhi jumlah hasil panen yang diperoleh.

Lain halnya dengan BEP produksi, BEP harga digunakan untuk mengetahui pada harga berapakah penjualan yang diperoleh sama dengan besarnya biaya yang dikeluarkan sehingga petani tidak untung dan tidak rugi. BEP harga merupakan perbandingan antara biaya total dengan produksi total. Distribusi petani padi berdasarkan BEP harga dalam berusahatani padi di Kecamatan Pitu Riawa Kecamatan Sidrap dapat dilihat pada Tabel 10.

Berdasarkan Tabel 10 diketahui bahwa 100\% petani padi di Kecamatan Pitu Riawa Kabupaten Sidrap menjual hasil panen berupa gabah kering panen (GKP) dengan harga di atas BEP harga. Dengan demikian, petani memperoleh keuntungan dalam berusahatani padi.

Tabel 10

Distribusi Petani Padi Menurut BEP Harga Usahatani Padi di Kecamatan Pitu Riawa Kabupaten Sidrap

\begin{tabular}{cccc}
\hline No. & Uraian & Jumlah Petani (orang) & Persentase (\%) \\
\hline 1. & Harga Produk $\leq$ BEP Harga & 0 & 0 \\
2. & Harga Produk > BEP Harga & 95 & 100 \\
\hline & Jumlah & $\mathbf{9 5}$ & $\mathbf{1 0 0}$ \\
\hline
\end{tabular}

Kelayakan suatu usaha dapat dilihat dari beberapa aspek, di antaranya R/C ratio dan titik impas (break even point) meliputi BEP produksi dan BEP harga. Hasil analisis kelayakan usahatani padi di Kecamatan Pitu Riawa Kabupaten Sidrap sebagai berikut:

\section{$R / C$ ratio}

Uji t ini menggunakan nilai 1 sebagai test value, sedangkan hipotesis yang diuji adalah sebagai berikut :

$\mathrm{H}_{0}: \mathrm{R} / \mathrm{C} \leq 1$

$\mathrm{H}_{1} \quad: \mathrm{R} / \mathrm{C}>1$

$\mathrm{H}_{0}$ ditolak jika $t_{\text {hitung }}>t_{\text {tabel }}$ dan $\mathrm{H}_{0}$ diterima jika $t_{\text {hitung }}<t_{\text {tabel }}$. Hasil pengujian hipotesis dengan menggunakan program SPSS 25,0 dapat dilihat pada Tabel 11.

Berdasarkan Tabel 11 diketahui bahwa thitung $>t_{\text {tabel. }}$. Dengan demikian $\mathrm{H}_{0}$ ditolak. Hal ini berarti bahwa usahatani padi yang dilakukan di Kecamatan Pitu Riawa Kabupaten Sidrap layak untuk dikembangkan. 
Tabel 11

Analisis R/C Ratio Usahatani Padi di Kecamatan Pitu Riawa Kabupaten Sidrap

\begin{tabular}{clcc}
\hline No. & \multicolumn{1}{c}{ Keterangan } & Nilai & A \\
\hline 1. & Rerata R/C & 4,113 & $5 \%$ \\
2. & Deviasi Standar & 1,108 & \\
3. & $t_{\text {hitung }}$ & 27,366 & \\
4. & $t_{\text {tabel }}$ & 1,985 & \\
5. & Test Value & 1 & \\
\hline
\end{tabular}

\section{BEP produksi}

Uji $\mathrm{t}$ ini menggunakan nilai BEP produksi sebagai test value, sedangkan hipotesis yang diuji adalah sebagai berikut :

$\mathrm{H}_{0} \quad$ : Total produksi $\leq \mathrm{BEP}$ produksi

$\mathrm{H}_{1}$ : Total produksi $>$ BEP produksi

$\mathrm{H}_{0}$ ditolak jika $t_{\text {hitung }}>\mathrm{t}_{\text {tabel }}$ dan $\mathrm{H}_{0}$ diterima jika $\mathrm{t}_{\text {hitung }}<\mathrm{t}_{\text {tabel }}$. Hasil pengujian hipotesis dengan menggunakan program SPSS 25,0 dapat dilihat pada Tabel 12.

Berdasarkan Tabel 12 diketahui bahwa thitung $>t_{\text {tabel. }}$. Dengan demikian $\mathrm{H}_{0}$ ditolak. Hal ini berarti bahwa usahatani padi yang dilakukan di Kecamatan Pitu Riawa Kabupaten Sidrap layak untuk dikembangkan.

Tabel 12

Analisis BEP Produksi Usahatani Padi di Kecamatan Pitu Riawa Kabupaten Sidrap

\begin{tabular}{clcc}
\hline No. & \multicolumn{1}{c}{ Keterangan } & Nilai & A \\
\hline 1. & Rerata BEP Produksi & 360,524 & $5 \%$ \\
2. & Deviasi Standar & 92,527 & \\
3. & thitung $_{\text {thel }}$ & 2,266 & \\
4. & t $_{\text {tabel }}$ & 1,985 & \\
5. & Test Value & 358 & \\
\hline
\end{tabular}

\section{BEP harga}

Uji $t$ ini menggunakan nilai BEP harga sebagai test value, sedangkan hipotesis yang diuji adalah sebagai berikut :

$\mathrm{H}_{0}$ : Harga produksi $\leq \mathrm{BEP}$ harga

$\mathrm{H}_{1}$ : Harga produksi $>\mathrm{BEP}$ harga

$\mathrm{H}_{0}$ ditolak jika $t_{\text {hitung }}>\mathrm{t}_{\text {tabel }}$ dan $\mathrm{H}_{0}$ diterima jika $t_{\text {hitung }}<t_{\text {tabel }}$. Hasil pengujian hipotesis dengan menggunakan program SPSS 25,0 dapat dilihat pada Tabel 13.

Tabel 13

Analisis BEP Harga Usahatani Padi di Kecamatan Pitu Riawa Kabupaten Sidrap

\begin{tabular}{clcc}
\hline No. & \multicolumn{1}{c}{ Keterangan } & Nilai & A \\
\hline 1. & Rerata BEP Harga & $1.286,916$ & $5 \%$ \\
2. & Deviasi Standar & 387,349 & \\
3. & $t_{\text {hitung }}$ & 3,395 & \\
4. & $t_{\text {tabel }}$ & 1,985 & \\
5. & Test Value & 1.152 & \\
\hline
\end{tabular}


Berdasarkan Tabel 13 diketahui bahwa $t_{\text {hitung }}>t_{\text {tabel. }}$. Dengan demikian $\mathrm{H}_{0}$ ditolak. Hal ini berarti bahwa usahatani padi yang dilakukan di Kecamatan Pitu Riawa Kabupaten Sidrap layak untuk dikembangkan.

\section{Kesimpulan}

Tingkat pendapatan petani padi di Kecamatan Pitu Riawa Kabupaten Sidrap sebesar Rp 13.624.627/MT/ha dan usahatani padi di Kecamatan Pitu Riawa Kabupaten Sidrap layak untuk diusahakan. Hal ini dapat dilihat dari nilai R/C lebih dari 1, yakni sebesar 4,24; produksi padi sebanyak $5.104 \mathrm{~kg}$ lebih dari BEP produksi sebanyak $358 \mathrm{~kg}$; dan harga padi sebesar Rp 4.890/kg berada di atas BEP harga sebesar Rp1.152/kg. Disarankan agar berbagai institusi yang berwenang dan mempunyai perhatian khusus bagi petani padi dapat segera bertindak jika ada kecenderungan penurunan harga mendekati 76,44\%, serta petani diharapkan dapat mempertahankan kepemilikan lahan yang dimiliki saat ini agar tetap lebih dari 732 $\mathrm{m}^{2}$ untuk tetap bisa memperoleh keuntungan dari kegiatan berusahatani padi.

\section{Daftar Pustaka}

Lumintang, Fatmawati M., 2013. Analisis Pendapatan Petani Padi di Desa Teep Kecamatan Langiwan Timur. EMBA, Vol. 1 No. 3, September 2013: 991-998.

Mardiyanto, Sudi, Yana Supriyatna, dan Nur Khoiriyah Agustin, 2005. Dinamika Pola Pemasaran Gabah dan Beras di Indonesia. Forum Penelitian Agro Ekonomi, Vol. 23 No. 2, Desember 2005: 115-131.

Ma'ruf, Muhammad Imam, dan Ken Suratiyah, 2010. Analisis Pertanian Stroberi di Kecamatan Rancabali Kabupaten Bandung, AgroEkonomi, Vol. 17 No. 2, Desember 2010: 185-200.

Munizar, Andi, dan Dance Tangakesalu, 2019. Analisis Pendapatan dan Kelayakan Usahatani Padi Sawah Sistem Hambur Benih Langsung di Desa Dolago Kecamatan Parigi Selatan Kabupaten Parigi Moutong. Agrotekbis, Vol. 7 No. 1, Februari 2019: 51-58.

Sudarto, Awaluddin Hipi, dan Hiryana Windiyani, 2018. Kajian Pengembangan Varietas Unggul Baru Padi Sawah dengan Pendekatan Pengelolaan Tanaman Terpadu di Dompu, Nusa Tenggara Barat. Penelitian Pertanian Tanaman Pangan, Vol. 2 No. 2, Agustus 2018: 95-99.

Supartama, Made, Made Antara, dan Rustam Abd Rauf, 2013. Analisis Pendapatan dan Kelayakan Usaha Padi Sawah di Subak Baturiti Desa Balinggi Kecamatan Balinggi Kabupaten Parigi Moutong. Agrotekbis, Vol. 1 No. 2, Juni 2013: 166-172.

Suratiyah, Ken, Djuwari, Supriyanto, dan Lestari Rahayu Waluyati, 2003. Studi Analisa Usaha Tani untuk Tujuh (7) Komoditas di Kabupaten Bantul. Fakultas Pertanian UGM dan BAPPEDA Kabupaten Bantul. Yogyakarta.

Suratiyah, K., 2016. Ilmu Usahatani. Jakarta : Penebar Swadaya.

Waluyati, Lestari Rahayu, 2001. Pola Tanam Optimal pada Lahan Pantai di Kabupaten Kulon Progo. Agro Ekonomi, Vol. VIII No. 2, Desember 2001 : 40-50. 